\title{
RESEARCH
}

Open Access

\section{The presence of human mesenchymal stem cells of renal origin in amniotic fluid increases with gestational time}

\author{
Md Shaifur Rahman ${ }^{1 \dagger}$, Lucas-Sebastian Spitzhorn ${ }^{1 \dagger}$, Wasco Wruck', Carsten Hagenbeck², Percy Balan²,
} Nina Graffmann ${ }^{1}$, Martina Bohndorf ${ }^{1}$, Audrey Ncube ${ }^{1}$, Pascale V. Guillot ${ }^{3}$, Tanja Fehm² and James Adjaye ${ }^{1^{*}}$

\begin{abstract}
Background: Established therapies for managing kidney dysfunction such as kidney dialysis and transplantation are limited due to the shortage of compatible donated organs and high costs. Stem cell-based therapies are currently under investigation as an alternative treatment option. As amniotic fluid is composed of fetal urine harboring mesenchymal stem cells (AF-MSCs), we hypothesized that third-trimester amniotic fluid could be a novel source of renal progenitor and differentiated cells.
\end{abstract}

Methods: Human third-trimester amniotic fluid cells (AFCs) were isolated and cultured in distinct media. These cells were characterized as renal progenitor cells with respect to cell morphology, cell surface marker expression, transcriptome and differentiation into chondrocytes, osteoblasts and adipocytes. To test for renal function, a comparative albumin endocytosis assay was performed using AF-MSCs and commercially available renal cells derived from kidney biopsies. Comparative transcriptome analyses of first, second and third trimester-derived AF-MSCs were conducted to monitor expression of renal-related genes.

Results: Regardless of the media used, AFCs showed expression of pluripotency-associated markers such as SSEA4, TRA-1-60, TRA-1-81 and C-Kit. They also express the mesenchymal marker Vimentin. Immunophenotyping confirmed that third-trimester AFCs are bona fide MSCs. AF-MSCs expressed the master renal progenitor markers SIX2 and CITED1, in addition to typical renal proteins such as PODXL, LHX1, BRN1 and PAX8. Albumin endocytosis assays demonstrated the functionality of AF-MSCs as renal cells. Additionally, upregulated expression of BMP7 and downregulation of WT1, CD133, SIX2 and C-Kit were observed upon activation of WNT signaling by treatment with the GSK-3 inhibitor CHIR99201. Transcriptome analysis and semiquantitative PCR revealed increasing expression levels of renal-specific genes (e.g., SALL1, HNF4B, SIX2) with gestational time. Moreover, AF-MSCs shared more genes with human kidney cells than with native MSCs and gene ontology terms revealed involvement of biological processes associated with kidney morphogenesis.

Conclusions: Third-trimester amniotic fluid contains AF-MSCs of renal origin and this novel source of kidney progenitors may have enormous future potentials for disease modeling, renal repair and drug screening.

Keywords: Amniotic fluid, Kidney, Renal progenitor cells, SIX2, Mesenchymal stem cells, Albumin endocytosis, Third trimester

\footnotetext{
* Correspondence: james.adjaye@med.uni-duesseldorf.de

${ }^{\dagger}$ Equal contributors

${ }^{1}$ Institute for Stem Cell Research and Regenerative Medicine, Medical Faculty,

Heinrich Heine University, Moorenstraße 5, 40225 Düsseldorf, Germany

Full list of author information is available at the end of the article
}

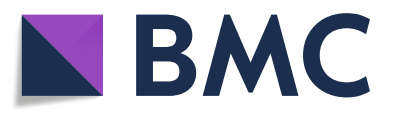

(c) The Author(s). 2018 Open Access This article is distributed under the terms of the Creative Commons Attribution 4.0 International License (http://creativecommons.org/licenses/by/4.0/), which permits unrestricted use, distribution, and reproduction in any medium, provided you give appropriate credit to the original author(s) and the source, provide a link to the Creative Commons license, and indicate if changes were made. The Creative Commons Public Domain Dedication waiver (http://creativecommons.org/publicdomain/zero/1.0/) applies to the data made available in this article, unless otherwise stated. 


\section{Background}

A functional kidney is essential for healthy living due to its major role in toxin and drug filtration. Globally, each year millions of patients require rapid kidney transplantation or dialysis to restore renal function [1, 2]. But the shortage of compatible organs, donor-associated diseases, ageing-associated factors and high cost of transplantation/dialysis are major hurdles [3]. Kidneyassociated dysfunctions are now a prioritized health concern and research area. A potential alternative source of renal cells are those derived from embryonic and induced pluripotent stem cells (ESCs and iPSCs) [4-9]. Clinical applications of pluripotent stem cell technologies are constrained by the risk of tumor formation, immunological rejection, legal as well as ethical concerns. In light of this, it is therefore important to find other sources of stem cells which are not tumorigenic, bear a broad differentiation potential and have a high renal regenerative potential.

The architecture and organization of the kidney is very complex and consists of numerous cell types [10] which can interchange identities by a very complex reciprocal interplay and interactions of stromal and epithelial cell lineages [9, 11]. Kidney mesenchymal cells have been demonstrated to express SIX2 and Cbp/p300-interacting transactivator 1 (CITED1) which are crucial for the selfrenewing capability $[11,12]$. Furthermore, the main kidney nephron-regulatory genes have been described, such as SALL1, PAX2, WT1, Cytokeratin 19 (CK19), CD133, Podocalyxin-like protein 1 (PODXL), HOXD11, HNF1B, BRN1, Lhx1 and Pax8 [13-18]. Adult and fetal bone marrow-derived mesenchymal stem cells (BM-MSCs) have been shown to be capable of repairing renal function deficits [19, 20]. BM-MSCs have potent immunosuppressive properties and their potential application in acute kidney injury animal models has been studied recently [21]. However, the use of adult BM-MSCs has some limitations such as the low number of MSCs in adult bone marrow, expression of ageing-associated factors, slow expansion rate, early senescence, inactive telomerase, shorter telomeres and restricted differentiation potential [22]. Due to the increasing number of patients with kidney diseases and limited cell-based therapeutic options, alternative renal progenitor cells and sources are clearly in need [23]. Amniotic fluid contains fetalderived differentiated and undifferentiated progenitor cells. In vitro, they can be expanded in distinct media formulations and exhibit a heterogeneous morphology with a preponderance of epithelioid and fibroblastoid mesenchymal-like cell shape [24]. In 2007, Perin et al. [25] demonstrated the potency of second-trimester amniotic fluid-derived MSCs (AF-MSCs) to form embryonic kidney structures in vitro. Later, they also showed that human AF-MSCs help in regenerating kidneys undergoing acute tubular necrosis in a rodent model [26-28]. In an animal model of acute renal injury, Camussi's research group confirmed these results and could show comparable efficacy between BM-MSCs and AF-MSCs [29]. Remarkably, the renal differentiation potential of AF-MSCs was demonstrated by producing chimeric organotypic renal structures from murine embryonic kidney cells and human AF-MSCs [30]. Although properties of human amniotic fluid cells such as the lack of immunogenicity and tumorigenicity, their anti-inflammatory properties and their high proliferative and differentiation potential are well described [31, 32], the exact origin of AF-MSCs is still unknown and controversial [33]. Before use in clinical applications, it is mandatory to elucidate the origin of AF-MSCs. Due to the fact that term amniotic fluid consists mostly of fetal urine [34], we hypothesized that AF-MSCs originate from the kidney and accumulate in the AF during fetal nephrogenesis.

Adult and neonatal human urine has been described as a source of kidney progenitor cells $[35,36]$. Secondtrimester AFCs have been described as an alternative source of podocytes [37] which express mesenchymal markers as well as the podocyte markers CD2AP and NPHS2 [25, 38]. In this study we isolated third-trimester human AF-MSCs and cultured them in distinct supporting media. AF-MSCs were characterized as a multipotent population of renal cells. By combining cellular, molecular, functional and transcriptome data, we conclude that third-trimester amniotic fluid harbors MSCs originating from the fetal kidney. These cells should be considered promising sources for studies on kidney development, nephrotoxicity tests, disease modeling, drug screening and future kidney-related cellular therapies.

\section{Methods}

Isolation and culture of human amniotic fluidic cells

Healthy donors who provided the first and secondtrimester amniotic fluid in this study provided written informed consent in accordance with the Declaration of Helsinki. Ethical approval was given by the Research Ethics Committees of Hammersmith \& Queen Charlotte's Hospitals (2001/6234) in compliance with UK national guidelines (Review of the Guidance on the Research Use of Fetuses and Fetal Material (1989), also known as the Polkinghorne Guidelines, Her Majesty's Stationery Office, London, 1989: Cm762) for the collection of fetal tissue for research. Third-trimester amniotic fluid samples from healthy donors were collected from the Department of Obstetrics and Gynaecology, Medical Faculty, Heinrich Heine University Düsseldorf, Germany, with informed patient consent as well as institutional ethical approval. Amniotic fluids were processed and AF-MSCs were isolated as described previously [32]. In 
brief, the cells were cultured in Prime XV or Chang C Medium (both Irvine Scientific, CA, USA), $\alpha M E M$ (Minimum Essential Medium Eagle Alpha Modification; Sigma) containing 10\% FBS, 1\% GlutaMAX and 1\% penicillin/streptomycin (Penstrep), MG30 (Cell Lines Service, Germany) or renal cell medium (RCM) consisting of high-glucose Dulbecco's Modified Eagle's Medium (DMEM) supplemented with 1\% Penstrep, 1\% glutamine, $10 \%$ FBS and SingleQuot Kit CC-4127 REGM at $37{ }^{\circ} \mathrm{C}$, $5 \% \mathrm{CO}_{2}$ and $5 \% \mathrm{O}_{2}$ (Lonza) $[39,40]$.

After the appearance of initially attached cells (days 4-7), the medium was changed and cells grew until reaching almost full confluency. The cells were then detached using TrypLE Express (Thermo Fisher Scientific) and prepared for further passaging and experiments. Urine-derived kidney progenitor cells and corresponding iPSCs (UM51, ISRM-UM51 [40]) and human renal epithelial cells from a biopsy (HREpCs; PromoCell, Heidelberg, Germany) were used as control cells.

\section{Immunofluorescence staining}

To analyze the cells for pluripotency, mesenchymal stem cell and renal cell specific markers, AF-MSCs were cultured in 12-well plates. After a washing step using PBS (Gibco), 4\% paraformaldehyde (PFA; Polysciences Inc., PA, USA) was used to fix the cells for $15 \mathrm{~min}$ at room temperature (RT). To increase the cell membranes' permeability, 1\% Triton X-100 (Carl Roth GmbH \& Co. KG, Karlsruhe, Germany) was applied to the fixed cells for 5 min followed by blocking of unspecific binding sites for $2 \mathrm{~h}$. For staining of intracellular proteins, this blocking buffer contained 10\% normal goat serum (NGS; Sigma), 0. 5\% Triton X-100, 1\% BSA (Sigma) and 0.05\% Tween 20 (Sigma), all dissolved in PBS. Triton and Tween were omitted when extracellular proteins were stained. Afterward, the primary antibodies (presented in Additional file 1: Table S1) were diluted in blocking buffer/PBS and incubated with the cells for $1 \mathrm{~h}$ at RT followed by several washing steps using $0.05 \%$ Tween 20 in PBS. The corresponding secondary Cy3-labeled or Alexa Fluor 488labeled antibodies (Thermo Fisher Scientific) and Hoechst 33,258 dye (Sigma-Aldrich Chemie GmbH, Taufkirchen, Germany) or DAPI (Southern Biotech) were added under light exclusion. For the actin filament staining, the toxin phalloidin 488 (A12370; Life Technologies) was used in a dilution of 1:200. A fluorescence microscope (LSM700; Zeiss, Oberkochen, Germany) was used for taking the pictures. All pictures were processed with the ZenBlue 2012 Software Version 1.1.2.0. (Carl Zeiss Microscopy GmbH, Jena, Germany).

\section{In-vitro differentiation assay}

In-vitro differentiation of the AF-MSCs into adipocytes, chondrocytes and osteoblasts was done employing the
StemPro Adipogenesis, Chondrogenesis, and Osteogenesis differentiation Kits (Gibco, Life Technologies, CA, USA). Media were replaced 2-3 times per week for 3 weeks, and the formation of intracellular lipid droplets (adipocytes), calcium mineralization (osteoblasts) and cellular aggregation toward clusters (chondrocytes) was observed from 14 to 21 days. After the differentiation process, fixation of the cells was done using $4 \%$ PFA for 30 min at RT. Subsequently, the cells were stained with Oil Red O for adipocytes, Alcian Blue for chondrocytes, and Alizarin Red S for osteoblasts as described previously [32]. A light microscope was used for imaging.

\section{Flow cytometric analysis}

The human MSC phenotyping kit (Miltenyi Biotec $\mathrm{GmbH}$, Bergisch Gladbach, Germany) was used to analyze the cell surface marker composition of the AFMSC samples $\left(2 \times 10^{5}\right.$ cells were used for each analysis), according to the manufacturer's instructions. The cells were washed with PBS and centrifuged at $300 \times g$ for 5 min. After resuspending the pellet in $100 \mu \mathrm{l}$ PBS, $0.5 \mu \mathrm{l}$ of the MSC phenotyping cocktail or of the isotype control cocktail were added and the tubes were mixed thoroughly. The MSC phenotyping cocktail is composed of a mixture of fluorochrome-coupled antibodies against various cell surface proteins (CD14-PerCP, CD20-PerCP, CD34-PerCP, CD45-PerCP, CD73-APC, CD90-FITC and $\mathrm{CD} 105-\mathrm{PE})$. The isotype phenotyping cocktail served as a negative control. The antibody binding took place at $4{ }^{\circ} \mathrm{C}$ for $10 \mathrm{~min}$ in the dark. Nonbound antibodies were washed out using $1 \mathrm{ml}$ PBS. After centrifugation at 300 $\times g$ for 5 min, cell fixation using 4\% PFA was done.

To analyze the AF-MSCs for pluripotency-associated cell surface markers (TRA-1-60, TRA-1-81, stage-specific embryonic antigen 4 (SSEA4)), corresponding prelabeled antibodies (anti-TRA-1-60-PE, human (clone REA157), number 130-100-347; anti-TRA-1-81-PE, human (clone REA246), number 130-101-410, and anti-SSEA-4-PE, human (clone REA101), number 130-098-369; Miltenyi Biotec GmbH, Bergisch Gladbach, Germany) were used. The staining procedure was carried out as already described. Until analysis via BD FACSCanto (BD Biosciences, Heidelberg, Germany) and CyAn ADP (Beckman Coulter, CA, USA), stained cells were kept at $4{ }^{\circ} \mathrm{C}$ in the dark. The FCSalyzer software version 0.9 .3 and Summit 4.3 software were used for data analysis.

\section{RNA isolation and quantitative PCR}

After single washing with PBS, TRIzol (Thermo Fisher) was added to the cells for $5 \mathrm{~min}$ at RT, and the cells were scraped off and stored at $-80{ }^{\circ} \mathrm{C}$. For isolation of the RNA, the Direct-zol RNA Miniprep Kit (Zymo Research, CA, USA) was used according to the manufacturer's instructions. All of the primers used were 


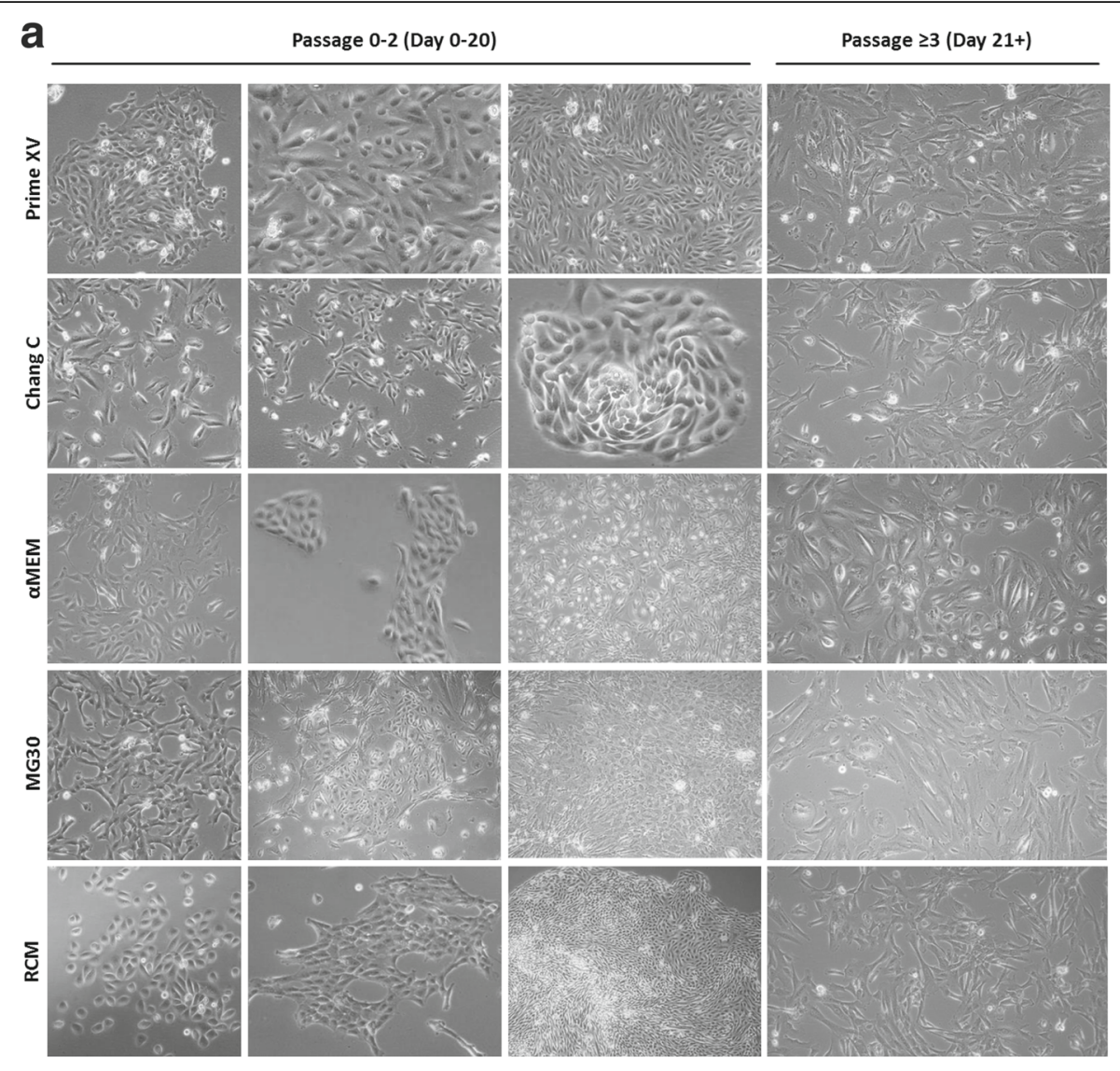

b

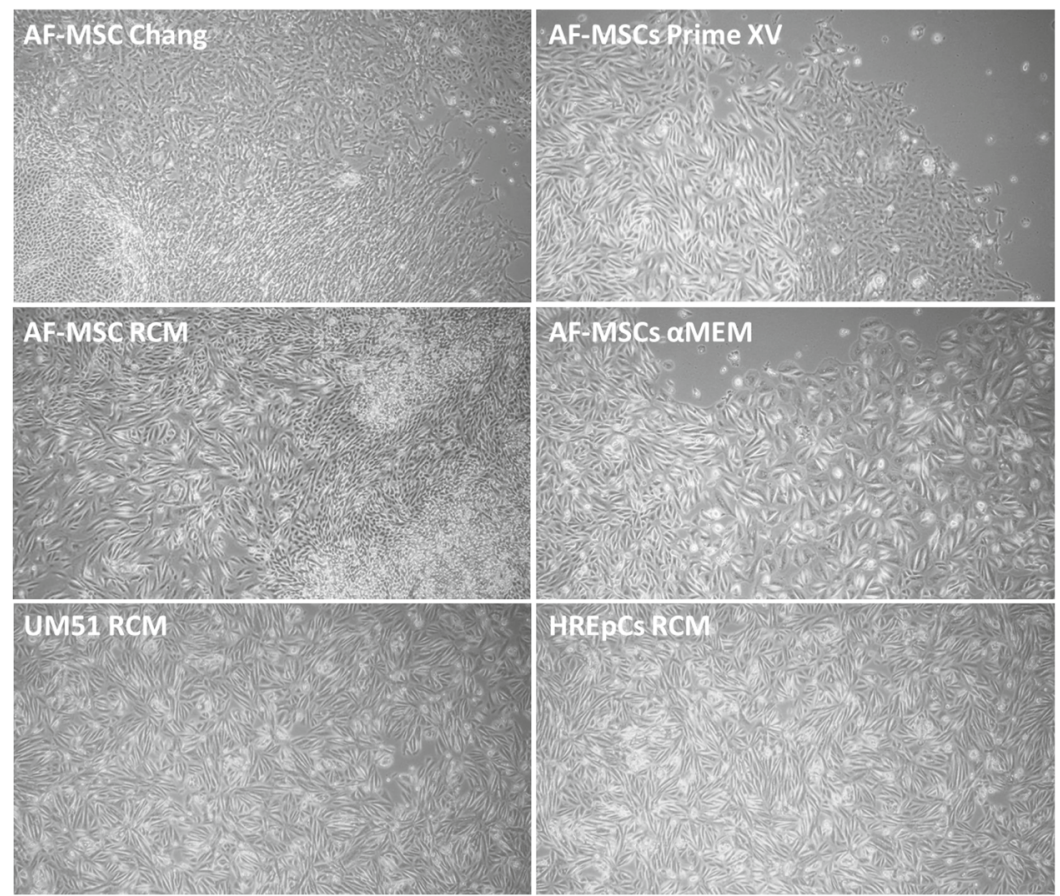

Fig. 1 (See legend on next page.) 
(See figure on previous page.)

Fig. 1 Initially attached heterogeneous AFCs display homogeneous cell morphology upon passaging and include typical kidney cell morphologies. Phenotypical complexity of AFCs observed, regardless of culture media composition within first two passages. Upon further passaging, cells became homogeneous with fibroblast-like morphology (a). During culture, subpopulation of cells observed which had similar morphology to distinct renaloriginated progenitor cells UM51 and HREpCs (b). AF-MSC amniotic fluid mesenchymal stem cell, HREpC human renal epithelial cell, aMEM minimum essential medium alpha modification, RCM renal cell medium

purchased from MWG (primer sequences and predicted sizes of amplicons presented in Additional file 1: Table S2). After checking the quality of mRNA, complementary DNA (cDNA) was synthesized with the TaqMan Reverse Transcription Kit (Applied Biosystems). A sample of $500 \mathrm{ng}$ of RNA was used for cDNA synthesis. The prepared mix of $20 \mu \mathrm{l}$ per sample consisted of $7.70 \mu \mathrm{l}$ $\mathrm{H}_{2} \mathrm{O}, 2 \mu \mathrm{l}$ reverse transcriptase buffer, $4.4 \mu \mathrm{l} \mathrm{MgCl}_{2}$ $(25 \mathrm{mM}), 1 \mu \mathrm{l}$ Oligo $(\mathrm{dT}) /$ random hexamer $(50 \mu \mathrm{M})$, $4 \mu \mathrm{l}$ dNTP mix $(10 \mathrm{mM}), 0.4 \mu \mathrm{l}$ RNase inhibitor $(20 \mathrm{U} /$ $\mu \mathrm{l})$ and $0.5 \mu \mathrm{l}$ reverse transcriptase $(50 \mathrm{U} / \mu \mathrm{l})$. For semiqPCR, a mixture of $25 \mu \mathrm{l}$ per sample contained the following: $11.375 \mu \mathrm{l} \mathrm{H} \mathrm{H}_{2} \mathrm{O}, 5 \mu \mathrm{l}$ of $1 \times$ Go-Taq G2 Hot Start Green PCR buffer, $4 \mu \mathrm{l}$ of $4 \mathrm{mM} \mathrm{MgCl} 2,0.5 \mu \mathrm{ldNTP}$ Mix (10 mM each), $1 \mu \mathrm{l}$ forward primer $(0.3 \mu \mathrm{M}), 1 \mu \mathrm{l}$ reverse primer $(0.3 \mu \mathrm{M}), 0.125 \mu \mathrm{l}(0.625 \mathrm{U})$ Hotstart Taq polymerase $(5 \mathrm{U} / \mu \mathrm{l})$ and $2 \mu \mathrm{l}$ cDNA. A PCR thermal cycler (PEQLAB, Erlangen Germany) was employed. After an initial denaturation step at $95^{\circ} \mathrm{C}$ for 2 min, 30 cycles followed with a denaturation step at $95{ }^{\circ} \mathrm{C}$ for $30 \mathrm{~s}$, an annealing step at the temperature specific for each primer (ranging from 55 to $63{ }^{\circ} \mathrm{C}$ ) for $30-35 \mathrm{~s}$ and an extension step at $72{ }^{\circ} \mathrm{C}$ for $30-40 \mathrm{~s}$. Detection of semiqPCR amplification products was performed by size fractionation on $2 \%$ agarose gel electrophoresis. Real-time quantitative PCR was performed in technical triplicates with Power SYBR Green Master Mix (Life Technologies) on a VIIA7 (Life Technologies) machine. Mean values were normalized to levels of the housekeeping gene ribosomal protein L37A. Results are depicted as mean values (\% of untreated control) with 95\% confidence interval.

\section{Albumin endocytosis assay}

To analyze the functional ability of the AF-MSCs to endocytose exogenous albumin, cells were plated at a density of $30 \%$ in 12 -well plates without coating. After 2 days, media were supplemented with $10 \mu \mathrm{M}$ CHIR dissolved in DMSO or the same volume of DMSO alone and the cells were allowed to differentiate for 2 days. After this time period the cells were washed once with PBS and incubated in new medium supplemented with $20 \mu \mathrm{g} / \mathrm{ml}$ of albumin from bovine serum (BSA), Alexa Fluor $^{\text {rm }} 488$ conjugate (catalog no. A13100; Thermo Fischer) for $1 \mathrm{~h}$. As endocytosis is an energy-dependent process, incubations were performed at $37^{\circ} \mathrm{C}$. After $1 \mathrm{~h}$ of incubation, however, cells were washed three times with ice-cold PBS and fixed with 4\% PFA for $15 \mathrm{~min}$. Cell-associated fluorescence was analyzed using an excitation wavelength of $488 \mathrm{~nm}$ and an emission wavelength of $540 \mathrm{~nm}$ and imaged using a florescence microscope (LSM700; Zeiss, Oberkochen, Germany). All pictures were analyzed with ZenBlue 2012 Software Version 1.1.2.0. (Carl Zeiss Microscopy GmbH, Jena, Germany). Human fetal foreskin cell line HFF1 (SCRC1041; ATCC) and fMSCs (kindly gifted from Prof. Richard O. C. Oreffo, Southampton, UK) served as control.

\section{Transcriptome analysis}

PrimeView Human Gene Expression Array Chips (Affymetrix; Thermo Fisher Scientific) were used for microarray experiments (conducted by BiologischMedizinisches Forschungszentrum, Düsseldorf, Germany). The gene expression profile for AF-MSCs, HREpCs, fMSCs, UM51 and ISRM-UM51 are provided online at the National Center of Biotechnology Information Gene Expression Omnibus. The affy package of the R/Bioconductor environment $[41,42]$ was used for further processing of the unnormalized bead summary data. After background correction, the data were transformed to a logarithmic scale (to base 2), and normalized by employing the robust multiarray average method. The heatmap. 2 function from the gplots package (http://CRAN.R-project. org/package=gplots) was employed to create cluster analysis and heatmaps. The correlation coefficients were calculated with Pearson correlation as a similarity measure (http://CRAN.R-project.org/package=gplots). Based on the results of the transcriptome analysis, the DAVID tool (https://david.ncifcrf.gov/) [43] was used to generate gene ontology terms and associated KEGG pathways [44] for the distinct gene sets.

\section{Results}

AFCs become homogeneous after several passages and contain a renal cell-like subpopulation

In-vitro growth of AFCs in monolayers preserves diversity of cell types irrespective of media, in particular within the first two passages. AFCs were isolated and expanded in various media (RCM, Prime XV, Chang C, MG30, $\alpha M E M$ ) under hypoxic conditions. Bright-field microscopic observation revealed a mixture of distinct cell types with a morphology of mesenchymal-like, epithelioid, spindle, cobble-stone and tubular shapes, of fetal-derived differentiated and undifferentiated progenitor cells (Fig. 1a). After 


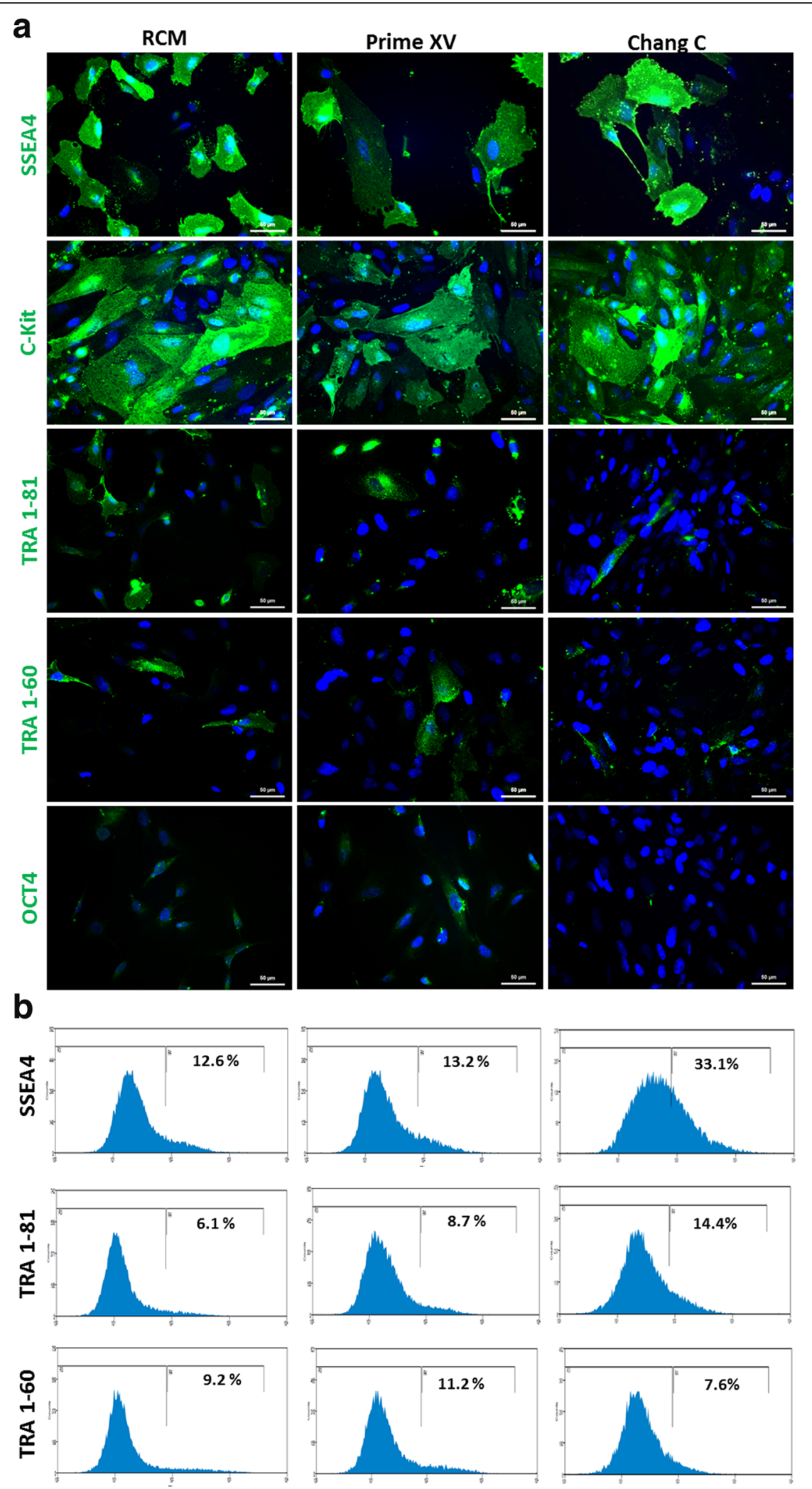

Fig. 2 (See legend on next page.) 
(See figure on previous page.)

Fig. 2 Pluripotency-associated stem cell marker expression of AFCs in distinct media. Immunofluorescent-based staining showed similar stem cellrelated protein expression in all three media conditions (RCM, Prime XV, Chang C). AFCs express SSEA4, C-Kit, TRA-1-60 and TRA-1-81. Cell nuclei stained using Hoechst (a). Flow cytometric analysis confirmed cell surface expression of SSEA4, TRA-1-60 and TRA-1-81 (b). RCM renal cell medium

passaging 3-4 times, the cells became more homogeneous with fibroblastic mesenchymal-like morphologies in all media except $\alpha M E M$ and MG30. In $\alpha M E M$ and MG30, cells attained an oval/egg-shaped morphology and had significantly decreased growth rates (Fig. 1a). Based on morphology, renal progenitor, undifferentiated and differentiated cell types were observed as subpopulations. The commercially available human kidney cell line HREpC as well as urine-derived renal cells (UM51) served as controls (Fig. 1b).

\section{AFCs express pluripotency-associated proteins}

To analyze the presence of pluripotent stem cellassociated markers in AFCs, both immunofluorescence staining and flow cytometry were performed. The AFC populations cultured in RCM, Prime XV and Chang C media were found to express SSEA4, C-Kit, TRA-1-60 and TRA-1-81. Expression of cytoplasmic and no nuclear octamer-binding transcription factor 4 (OCT4) was observed at early passages in RCM and Prime XV (Fig. 2a). However, the percentages of cells positive for the investigated markers (SSEA4, C-Kit, TRA-1-60 and TRA-1-81) were consistent with the flow cytometric data. Approximately $13 \%$ of the RCM cultured cells were positive for SSEA4, 9\% for TRA-1-60 and 6\% for TRA1-81. AFCs cultured in Prime XV showed positivity rates of $13.2 \%$ for SSEA4, $8.7 \%$ for TRA-1-60 and $11.2 \%$ for TRA-1-81. Previously performed flow cytometric analysis for cells cultured in Chang $\mathrm{C}$ media revealed $33.1 \%$ SSEA4, $14.4 \%$ TRA-1-60 and 7.6\% TRA-1-81 positive cells [32] (Fig. 2b).

\section{AFCs express proteins related to MSCs as well as CK19 and show multilineage differentiation potential in vitro} AFCs cultured in all three media compositions (RCM, Prime XV and Chang C) expressed the typical mesenchymal marker Vimentin and not E-Cadherin. Additionally, subpopulations of the cells were positive for CK19, a marker for renal epithelial cells. The expression of CD133/Prominin-1, as a marker for multipotent progenitor cells, was also observed in all conditions. HREpCs, derived from kidney biopsies, were used as renal reference cells and also showed positivity for Vimentin, CD133 and CK19 (Fig. 3a). To analyze the typical MSC surface marker expression in AFCs, flow cytometric analysis was conducted. The presence of CD73, CD90 and CD105 could be identified in all cases; interestingly, cells in RCM had the highest level of expression. However, all cell preparations were devoid of the hematopoietic markers CD14, CD20, CD34 and CD45 (Fig. 3b, [32]). These features establish and confirm these cells as bona fide AF-MSCs.

To investigate the differentiation capacity of the AFCs, the cells were subjected to adipocyte, chondrocyte and osteoblast differentiation for 3 weeks. Successful differentiation into adipocytes was observed by Oil Red O staining of emerging fat droplets surrounding the cell nuclei. During chondrogenic differentiation the cells aggregated, and Alcian Blue staining showed the presence of emerged proteoglycans within the developed cell clusters. Osteogenic lineage differentiation was shown by Alizarin Red S staining of developed calcium deposits (Fig. 3c).

\section{AF-MSCs express renal markers irrespective of in-vitro culture media composition}

To validate our hypothesis that third-trimester AF-MSCs harbor renal progenitor cells, we analyzed AF-MSCs cultured in RCM, which is a medium formulated for kidney cells, for the expression of kidney-associated markers SIX2, CITED1, LHX1, PODXL, BRN1 and Paired-BoxProtein 8 (PAX8)-these were positive. Prime XV and Chang C, specialized for AFC culture, also supported expression of the renal markers. The commercially bought human kidney cells HREpCs served as a positive control. These results imply that AF-MSCs are of nephrogenic origin and the phenotype is maintained irrespective of the media used (Fig. 4).

\section{AF-MSCs are able to transport albumin}

Albumin endocytosis is a criterion defining renal cells. To analyze the ability of AF-MSCs to take up and release albumin, fluorescent dye-coupled Alexa Fluor ${ }^{\mathrm{Tm}}$ 488-labeled albumin was used. It could be shown that the temperature-dependent $\left(37^{\circ} \mathrm{C}\right)$ uptake of albumin (1 $\mathrm{h}$ incubation) by AF-MSCs was higher in comparison to fetal MSCs (fMSCs) and human fetal foreskin cell HFF1. This held true for both progenitor and differentiated cells (Fig. 5a). To differentiate AF-MSCs, we treated the cells with $10 \mu \mathrm{M}$ CHIR99021 (WNT pathway activation by GSK3 inhibition) for 2 days and observed morphological changes from fibroblastic to elongated tubular shape (Fig. 5b), resulting in decreased expression of progenitor markers C-Kit and SIX2. The expression and localization of WT1 switched from nuclear to cytoplasmic upon CHIR99021 treatment whereas Nephrin (NPHS1) expression was stable (Fig. 5c) as detected at 


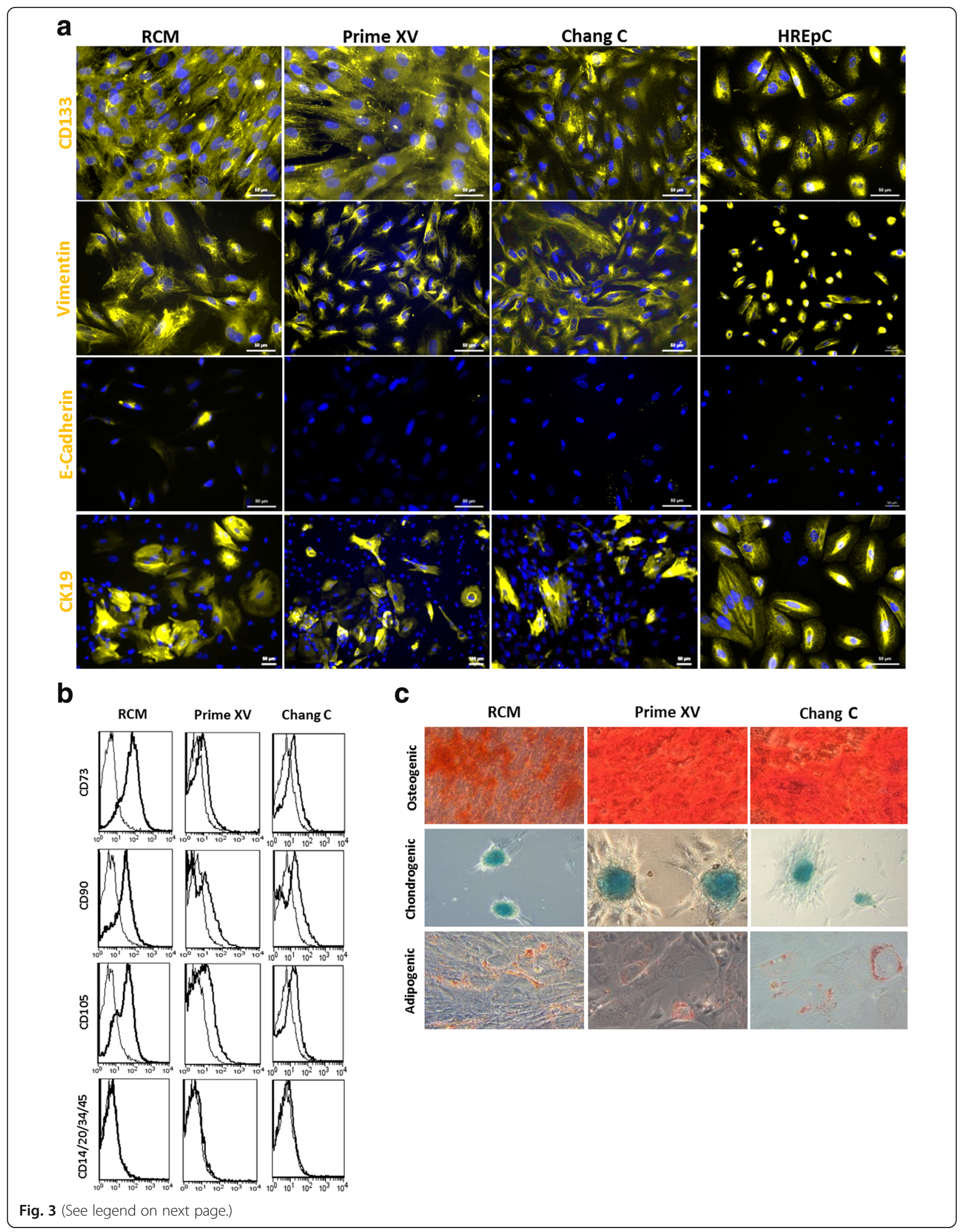


(See figure on previous page.)

Fig. 3 AFCs express typical MSC-associated proteins as well as CK19 and show multilineage differentiation potential in vitro. AFCs cultured in distinct media compositions stained positive for Vimentin and CD133 but negative for E-Cadherin. CK19, an established kidney epithelial marker, also expressed. Cell nuclei stained using Hoechst/DAPI (a). Flow cytometry-based analysis confirmed expression of MSC markers CD73, CD90 and CD105, and negativity for hematopoietic markers CD14, CD20, CD34 and CD45 (antibody isotype controls represented by thin lines; bold lines indicate histograms of distinct proteins) (b). Analysis of multilineage differentiation capacity of AF-MSCs revealed Alizarin Red staining of osteoid matrix-like structure in osteogenic medium, Alcian Blue staining of proteoglycans in chondrogenic media and lipid droplet formation around the cells in adipogenic media (c). HREpC human renal epithelial cell, RCM renal cell medium

the protein level via immunofluorescent-based staining. Real-time RT PCR revealed downregulation of SIX2, WT1 and CD133 and activation of kidney-associated bone morphogenic protein 7 (BMP7) (Fig. 5d). Based on our experimental data we derive a scheme describing CHIR99021-mediated WNT activation and its influence on differentiation or self-renewal (Fig. 6). Self-renewal (inactive WNT signaling) is maintained by elevated expression of the renal progenitor markers SIX2, WT1 and CD133 (stem cell proliferation marker) and downregulated expression of $B M P 7$. In contrast, upon activation of canonical WNT signaling by GSK3 $\beta$ inhibition with CHIR99021, AF-MSCs exit self-renewal and differentiate as a consequence of elevated $B M P 7$ expression and downregulation of SIX2, WT1 and CD133 respectively.

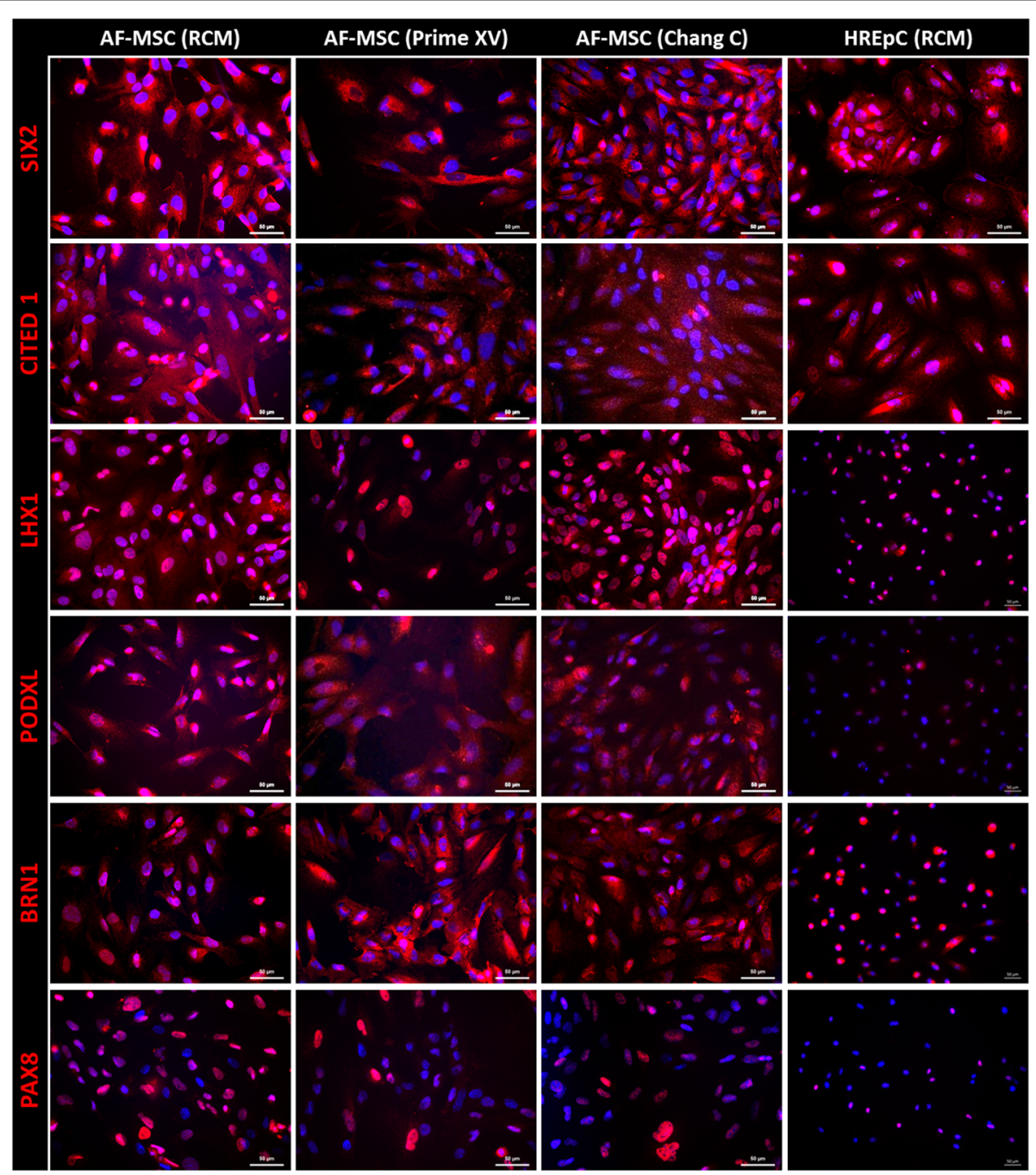

Fig. 4 Renal-specific marker expression in AF-MSCs. Immunofluorescent-based images showing expression and localization of SIX2, CITED1, PAX8, BRN1, PODXL and LHX1 in AF-MSCs cultured in either RCM, PrimeXV or Chang C. HREpCs cells served as positive control. Cell nuclei stained using Hoechst/DAPI. AF-MSC amniotic fluid mesenchymal stem cell, HREpC human renal epithelial cell, RCM renal cell medium 

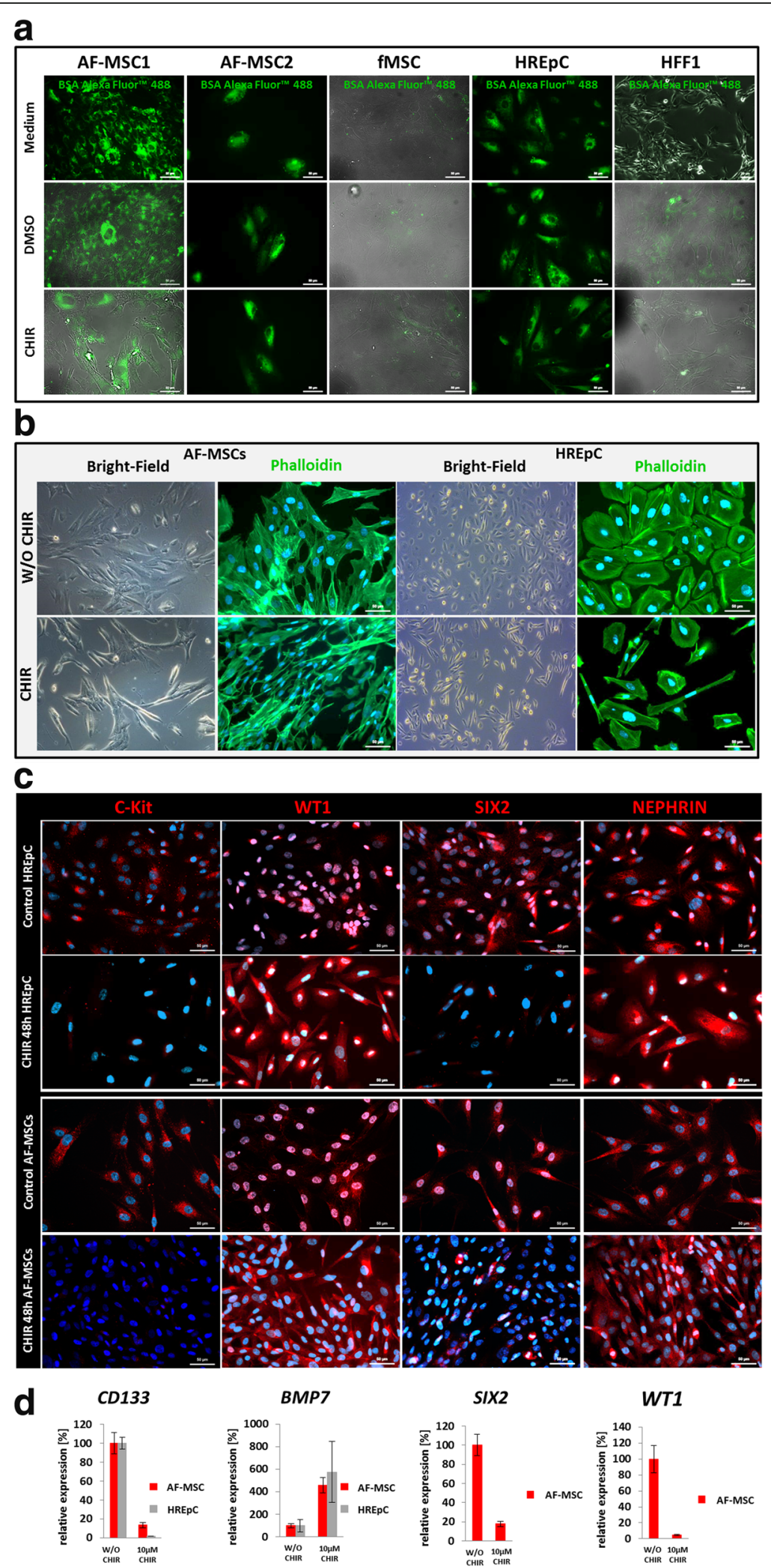

Fig. 5 (See legend on next page.) 
(See figure on previous page.)

Fig. 5 Functional characterization of AF-MSCs as renal cells. Regardless of differentiated or undifferentiated AF-MSC status, functional albumin endocytosis observed at significantly higher levels than in HFF1 and fetal MSCs (fMSC) when cells incubated with albumin at $37^{\circ} \mathrm{C}$ (a). Activation of WNT signaling by supplementation with GSK3-inhibitor CHIR99021 led to differentiation into tubular looking cells, shown by phalloidin staining (b). WT1 localization switch from nucleus to cytoplasm, Nephrin expression retained and C-Kit and SIX2 expression decreased (c). Cell nuclei stained using Hoechst/DAPI. qRT-PCR of CHIR differentiated cells clearly showed downregulation of renal undifferentiated progenitor markers CD133, SIX2 and WT1 and upregulation of the differentiation marker BMP7 (d). AF-MSC amniotic fluid mesenchymal stem cell, DMSO dimethylsulfoxide, fMSC fetal mesenchymal stem cell, HFF human foreskin fibroblast, HREpC human renal epithelial cell, w/o without

\section{Increased appearance of renal-associated genes in AFCs} correlates with gestational time

Taking advantage of previously published transcriptome data [45], related to renal system development from first and second-trimester AFCs, we analyzed gene set enrichments and related GOs from T1 (first trimester), T2 (second trimester) and T3 (third trimester). Interestingly, the number of expressed kidney-associated genes increased with gestational time. From the predictions based on the datasets, we observed that most of the renal developmental-related genes (eight genes) were expressed in the third trimester. Subsequently, only four genes were identified to be present in the second trimester and none was predicted to be expressed in the first trimester. In line with this, no kidney development-related GO terms were found for AFC samples from the first trimester, $10 \mathrm{GOs}$ were shown for the second and 12 GOs in the third trimester, thus implying an increasing renal expression pattern during fetal kidney development which is also shown in a heatmap generated from the transcriptome data (Fig. $7 \mathrm{a}-\mathrm{c}$ ). These data were validated by semi-qPCR of cDNA samples obtained from the mRNA of AFCs/AF-MSCs from the first, second, early third and late third trimesters. We did not detect renal gene expression from the first-trimester samples; in contrast, $P A X 8$ and $S A L L 1$ could be detected in the second and third-trimester samples. In contrast to this, third-trimester cells exclusively expressed SIX2, PAX2, LHX1, WT1, HNF1B, BRN1, NPHS1 and SALL4 (Fig. 7d).
Transcriptome analysis of third-trimester AF-MSCs reveals involvement in kidney specific biological processes

To reveal the AF-MSC identity, the cells' transcriptomes were compared to HREpCs, UM51 (urine-derived SIX2positive renal cells) and UM51-derived iPSCs (ISRMUM51). Using cluster dendrogram analysis, AF-MSCs were shown to cluster together with two different kidney cells and apart from the iPSCs (Fig. 8a). This is also shown by Pearson correlation coefficient calculation (Fig. 8b), revealing a value of 0.9095 for AF-MSC 1 and UM51 and a value of 0.955 for AF-MSC 1 and HREpCs. Next, we wanted to focus on genes shared amongst the AF-MSCs and the other two renal cell types. Since UM51, HREpCs and AF-MSCs showed expression of MSC markers, a sample of bone marrow-derived fetal MSCs was included in the Venn diagram, to allow focus on commonly expressed genes in AF-MSCs, UM51 and HREpCs but not in fMSCs (409 genes) (Fig. 8c). Using these genes, a GO term analysis was conducted. Among the top 20 GOs (Fig. 8d), 11 GOs were connected to kidney development-related biological processes such as "renal tubule development" and "nephron epithelium development". The significant KEGG pathways resulting from the 409 shared genes are shown in Fig. 8e, revealing stem cell-related pathways such as "TGF-beta signaling pathway" and "Hedgehog signaling pathway". The complete gene lists, GOs (BP, CC, MF) and the KEGG pathways for each single group as well as for a group

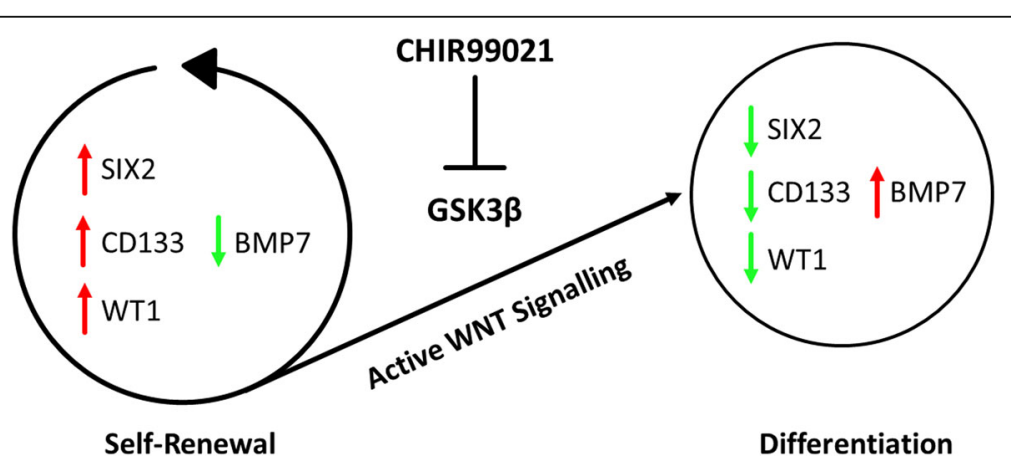

Fig. 6 WNT mediated cell fate decisions in AF-MSCs. Self-renewal renal progenitor cells maintained when WNT signaling is inactive due to sustained upregulated expression of SIX2,WT1 and CD133 and downregulation of BMP7 on mRNA level. Upon activation of canonical WNT signaling (i.e., CHIR99021-mediated GSK3B inhibition) there is an exit of self-renewal, due to upregulated expression of BMP7, but downregulation of WT1, SIX2 and CD133 expression on mRNA level 


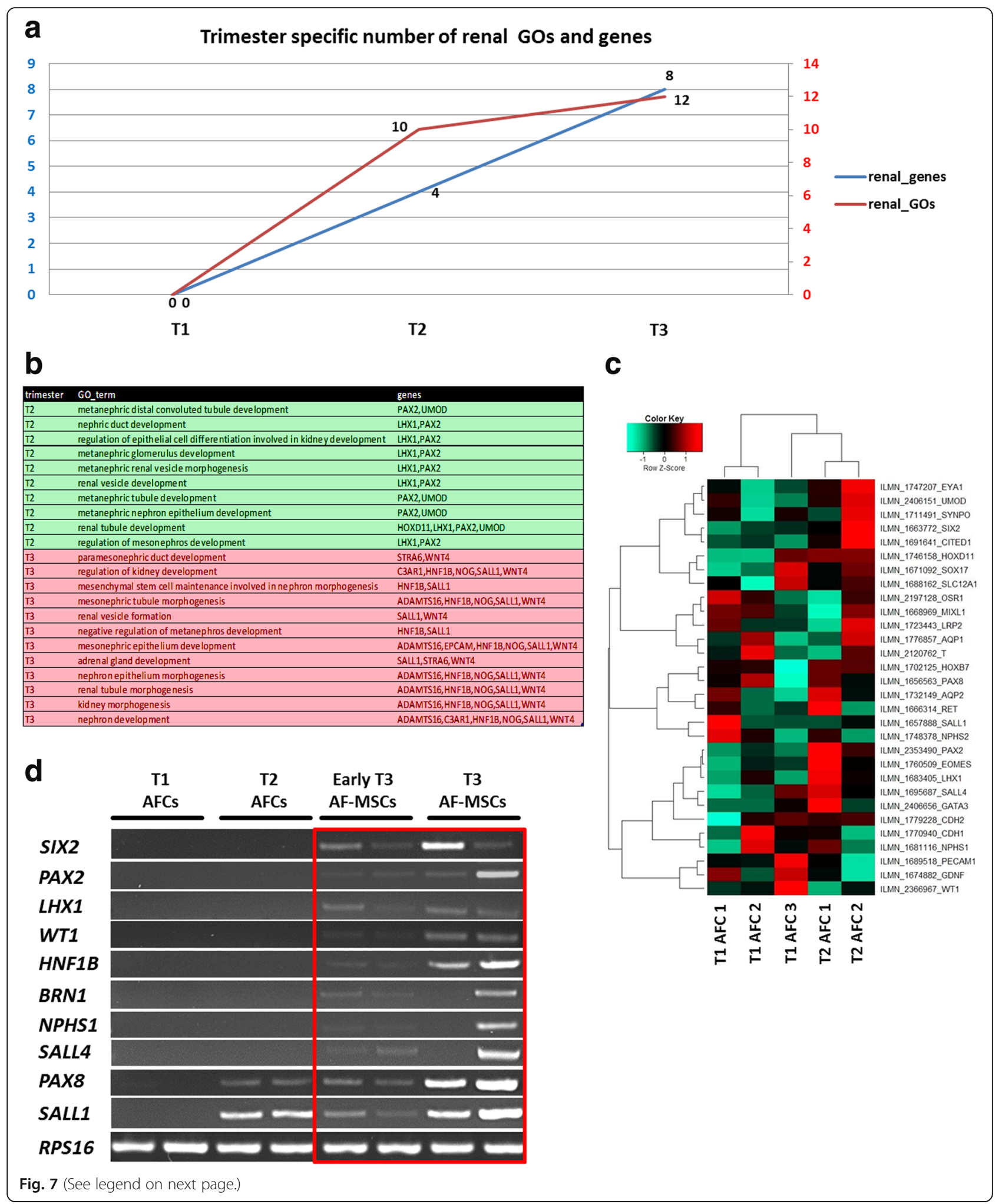




\section{(See figure on previous page.)}

Fig. 7 Expression levels of renal-specific genes in AFCs increase with gestational time. Number of renal-enriched genes (blue line) and GOs of trimester-specific AFCs (red line) indicates increasing pattern during fetal kidney development (a). Differentially expressed genes involved in nephron development in second and third-trimester AFCs. Gene-set enrichment analysis revealed expression of genes from different renal developmental compartments such as metanephros development (ADAMTS16, EPCAM, HNF1B, NOG, SALL1, WNT4), metanephric mesenchyme development (HNF1B, SALL1), renal tubule development (HOXD11, LHX1, PAX2, UMOD), metanephric nephron and tubule development (PAX2, UMOD), and metanephric glomerulus and mesonephros development $(L H X 1, P A X 2)(\mathbf{b})$. Heatmap showing relative expression of genes involved in nephrogenesis from existing published data of AFCs from first and second trimester (c). Semi-qPCR of renal genes in AFC/AF-MSC samples from first, second, early third and late third trimester. Gel bands indicating enriched expression of renal genes in third trimester boxed in red (d). AFC amniotic fluid cell, AF-MSC amniotic fluid mesenchymal stem cell, GO gene ontology, T1 first trimester, T2 second trimester, T3 third trimester

consisting of AF-MSCs, UM51 and HREpCs are provided in Additional files 2, 3 and 4.

\section{Discussion}

Amniotic fluid cells display a spectrum of morphologies (Fig. 1a) depicting their composition of fetal-derived differentiated and undifferentiated progenitor cells [24, 33]. In the majority of studies, the heterogeneity of AFderived cells has led to conflicting results and uncertainty regarding the identity of the cell population, in particular the origin of the third-trimester AFCs [37]. In our earlier work it could be shown that firsttrimester AFCs have a germ cell origin [45]. Remarkably, we observed that third-trimester AFCs have similar morphologies when compared to urine-derived cells and human kidney biopsy-derived cells (Fig. 1b), as shown by others [46-50]. It is well known that AF contains various cell types which originate mostly from fetal urine $[34,51]$ and the appearance of cells in the amniotic fluid/fetal urine increases in number with gestational age. Furthermore, it has also been shown recently that urine cells have a kidney origin [35-37, 40]. In studies on full-term male fetal AF-MSC transcriptomes, we and others found that most of the expressed genes were related to kidney and skeletal system development $[32,37]$. Nevertheless, the phenotypes of AFCs obtained during culture were dictated by culture conditions [52] and by the passage number. Initially, we cultured the cells in five distinct media, namely RCM, Prime XV, Chang C, MG30 and $\alpha$ MEM. Regardless of the media used, homogeneous spindle-shaped mesenchymal like cells were observed after a few passages, except for $\alpha M E M$ and MG30 which also led to decreased growth rates. So, these media were excluded from further analysis.

In this study, the third-trimester AFCs were shown to maintain expression of pluripotency-associated stem cell markers C-Kit, SSEA4, TRA-1-60 and TRA-1-81 but not nuclear OCT4 (Fig. 2a), which has also been shown for a subpopulation of urine-derived stem cells [46, 48]. C-kit was also identified to be expressed at the loop of Henley and distal tubules of murine kidney [53]. Secondtrimester human nephron progenitor cells were shown to have elevated expression of NANOG and OCT4 [14].
These data suggests that pluripotency-associated gene/ protein expression decreases with gestational time.

Third-trimester AFCs investigated in the present work expressed the mesenchymal marker Vimentin, typical MSC cell surface markers CD73, CD90, and CD105 as well as the stem cell marker CD133. Furthermore, the cells differentiated into adipocytes, osteocytes and chondrocytes (Fig. $3 \mathrm{a}-\mathrm{c}$ ), which has also been reported for cells derived from human kidneys [13], and hence we refer to the cells as AF-MSCs. In support of our findings, AFCs as well as cells derived from preterm neonatal urine were described to be positive for Vimentin and CD133 but negative for hematopoietic cell markers [35], which also was confirmed for fetal and adult kidney-derived cells [13, 14, 54]. In addition, our AFMSCs also express CK19 (Fig. 3a) as shown previously for human kidney cells [53]. It has been described that subpopulations of renal cells exist with MSC-specific morphology and marker expression (CD73, CD105) which additionally express metanephric mesenchyme markers such as SIX2, CITED1 and PAX2 [37, 54].

As the AF-MSCs share similar properties with neonatal urine cells and human renal cells with respect to pluripotency-associated and mesenchymal marker expression, and multipotent differentiation potential, we assumed, as shown in the 1970s [51], that AFCs originate from fetal kidney. This hypothesis is supported by a recent review describing that cells leave the fetal kidney during the transition from the pronephron to the metanephron, and reside within AF [37]. To confirm, we investigated AF-MSCs cultured in RCM, Chang $\mathrm{C}$ and Prime XV for the expression of typical renal markers such as SIX2, CITED1, PODXL, LHX1, BRN1 and PAX8. Irrespective of the used media, the third-trimester AF-MSCs expressed all of these markers (Fig. 4). In line with our results, nephron progenitor cells derived from the developing human kidney as well as from neonatal urine were previously reported to express the investigated marker [14, 15, 35, 55, 56].

We also investigated uptake of exogenous albumin as a key kidney function, which has been shown for human renal cells [57-59] as well neonatal urine cells [35]. Third-trimester AF-MSCs and HREpCs showed albumin endocytosis whereas fMSCs and HFF1 did not 


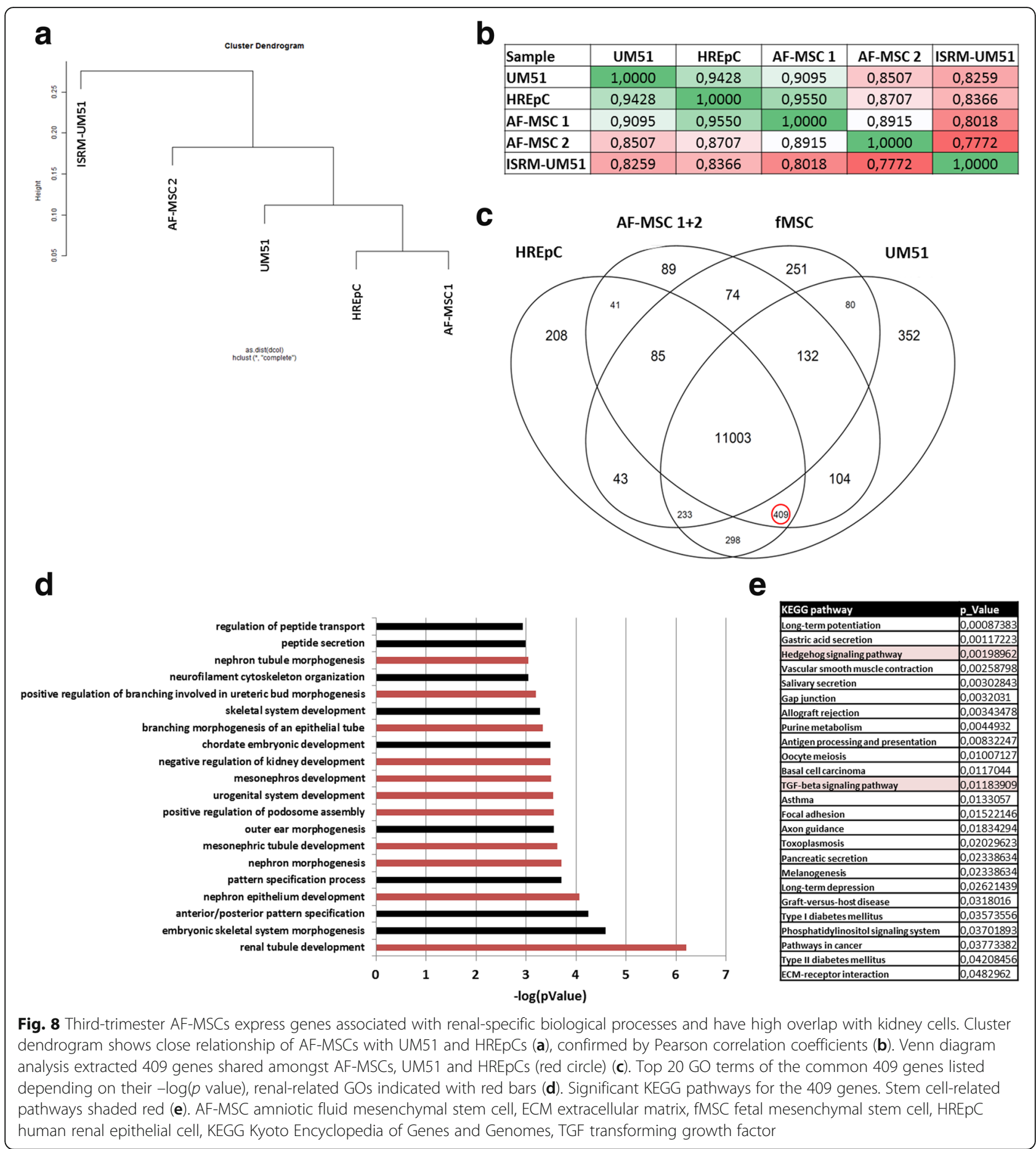

(Fig. 5a). Further, we analyzed the changes in morphology and protein/gene expression in the AF-MSCs upon differentiation by activation of WNT signaling as a consequence of inhibition of GSK3 using CHIR99201. Cell shapes became elongated and expression of renal progenitor markers C-KIT and SIX2 decreased, WT1 expression translocated from the nucleus to the cytoplasm and Nephrin expression remained cytoplasmic, which was also confirmed for cells isolated directly from a human kidney biopsy $[37,60]$. The translocation of WT1 expression from the nucleus to cytoplasm has been described previously [61]. The cytoplasmic expression of WT1 will denote a loss of transcription factor activity.

Moreover, qRT-PCR revealed that the differentiated AF-MSCs acquired upregulated BMP7 expression with 
parallel decreased SIX2, WT1 and CD133 expression (Fig. 5d), as shown previously $[62,63]$. One possible explanation for our observations could be that the antibody recognizes an epitope present on a variant of WT1 which we could not detect with our primers. Of course this is speculation and more studies are required to substantiate this observation.

Since nephrons are generated during the second and third trimesters [64], a synergistic relation between expression of kidney-associated genes in AF-MSCs and the gestational period can be postulated. To address this, we analyzed gene expression from previously published transcriptome data $[32,45]$ and performed a semiquantitative PCR of first, second and third-trimester samples to investigate any possible relationship between gradual expressions of renal genes with gestational time. The third-trimester AF-MSCs expressed increasing number of genes and GOs compared to second-trimester cells (Fig. 7a, b, d). For future research it would be of high value to have AF samples obtained from gestational week-wise time points to better understand the impact of the temporal developmental stage of the fetal kidney on the composition of the AF and likewise the identity of AF-MSCs. Cluster dendrogram analysis based on the transcriptome data showed that AF-MSCs cluster apart from pluripotent cells and cluster together with kidneyderived cells (Fig. 8a, b). In line with this, AF-MSCs shared more genes with human kidney cells UM51 and HREpCs than with fetal MSCs (Fig. 8c). Furthermore, GO analysis focusing on biological processes revealed the involvement of genes associated mostly with kidney development (Fig. 8d), which also can be observed in our previous analysis of AF specific genes [32].

Since the kidney is a complex organ and is composed of a multitude of different cell types, sorting and specification of distinct kidney cells from the amniotic fluid needs to be investigated.

Nevertheless, our results identify third-trimester human amniotic fluid-derived mesenchymal stem cells as of renal origin. As we have demonstrated before that these AF-MSCs also secrete immunomodulatory factors, they are highly suitable for transplantation, for example in chronic/acute kidney disease or graft versus host disease. These findings qualify these cells and the iPSCs derived from them as potent cells that can be used in the future for research on nephrogenesis, for modeling kidney-related diseases and for drug screening in combination with tissue engineering approaches such 3D organoid formation to further improve mimicking of kidney features in vitro.

\section{Conclusions}

We have demonstrated that third-trimester human AFCs originated from fetal kidney are mesenchymal stem cells
(AF-MSCs) with retained renal cell gene expression and functionality. AFCs/AF-MSCs have been widely investigated; however, to date only a limited number of studies have attempted to reveal their enigmatic origin. Our results add an important milestone for the usefulness of these cells as a suitable source for future studies related to nephrogenesis, derivation of iPSCs, nephrotoxicity tests and kidney disease-related cell replacement therapies.

\section{Additional files}

Additional file 1: Table S1. Antibodies used in this study Table S2. Primers used for semiquantitative and quantitative real-time PCR. (DOCX 18 kb)

Additional file 2: Gene list of exclusive groups and shared genes of AF-MSCs, HREpCs and UM51. (XLS 995 kb)

Additional file 3: GOs of exclusive groups and shared genes of AF-MSCs, HREpCs and UM51. (XLS $331 \mathrm{~kb}$ )

Additional file 4: KEGG pathways of exclusive groups and shared genes of AF-MSCS, HREpCs and UM51. (XLSX $76 \mathrm{~kb}$ )

\section{Abbreviations}

AF: Amniotic fluid; AFC: Amniotic fluid cell; AF-MSC: Amniotic fluid mesenchymal stem cell; BM-MSC: Bone marrow-derived mesenchymal stem cell; BSA: Bovine serum albumin; CD: Cluster of differentiation;

DAVID: Database for Annotation, Visualization and Integrated Discovery; ESC: Embryonic stem cell; FBS: Fetal bovine serum; fMSC: Fetal mesenchymal stem cell; GO: Gene ontology; HFF: Human foreskin fibroblast; HREpC: Human renal epithelial cell; iPSC: Induced pluripotent stem cell; KEGG: Kyoto Encyclopedia of Genes and Genomes; aMEM: Minimum essential medium alpha modification; MSC: Mesenchymal stem cell; PBS: Phosphate buffered saline; PCR: Polymerase chain reaction; RCM: Renal cell medium; REGM: Renal epithelial growth medium; RT: Room temperature; T1: First trimester; T2: Second trimester; T3: Third trimester

\section{Acknowledgements}

The authors thank Prof. Richard O. C. Oreffo, Centre for Human Development, Stem Cells and Regeneration, Faculty of Medicine, University of Southampton, UK for providing the fMSCS.

\section{Funding}

JA and TF acknowledge support from the Medical Faculty, Heinrich-HeineUniversity, Düsseldorf, Germany. In addition, JA and MSR acknowledge support from the German Academic Exchange Service (DAAD-91607303).

\section{Availability of data and materials}

The data and cells described in this manuscript can be made available upon request. The transcriptome data are available online at the National Center of Biotechnology Information (NCBI) Gene Expression Omnibus.

\section{Authors' contributions}

JA, TF, MSR and L-SS conceived the idea and designed the experiments. $\mathrm{CH}$ and PB collected third-trimester amniotic fluid samples. PVG collected first and second-trimester amniotic fluid samples and prepared the corresponding RNA. MB performed immunofluorescence staining of the HREpCs, and designed the renal specific primers. NG performed real-time PCR analysis. WW performed bioinformatic analysis. AN performed analysis of the CHIR99021-treated AFMSCS and HREpCs. MSR and L-SS isolated the AFCs from third-trimester AF and characterized the AFCS/AF-MSCS. MSR and L-SS wrote the manuscript and JA edited it. All authors read and approved the manuscript.

\section{Ethics approval and consent to participate}

Full-term amniotic fluid samples from healthy donors were collected from the Department of Obstetrics and Gynaecology, Medical Faculty, Heinrich Heine University Düsseldorf, Germany, with informed patient consent as well as institutional ethical approval. 


\section{Consent for publication}

All authors have agreed to submit this manuscript for publication.

\section{Competing interests}

The authors declare that they have no competing interests.

\section{Publisher's Note}

Springer Nature remains neutral with regard to jurisdictional claims in published maps and institutional affiliations.

\section{Author details}

${ }^{1}$ Institute for Stem Cell Research and Regenerative Medicine, Medical Faculty, Heinrich Heine University, Moorenstraße 5, 40225 Düsseldorf, Germany. ${ }^{2}$ Department of Obstetrics and Gynaecology, Medical Faculty, Heinrich Heine University Düsseldorf, Moorenstraße 5, 40225 Düsseldorf, Germany. ${ }^{3}$ Institute for Women's Health, Maternal and Fetal Medicine Department, University College London, London WC1E 6HX, UK.

Received: 24 January 2018 Revised: 19 March 2018

\section{Accepted: 10 April 2018 Published online: 25 April 2018}

\section{References}

1. Kellum JA, Hoste EA. Acute kidney injury: epidemiology and assessment. Scand J Clin Lab Invest Suppl. 2008;241:6-11.

2. Hoste EA, Schurgers M. Epidemiology of acute kidney injury: how big is the problem? Crit Care Med. 2008:36(4 Suppl):S146-51.

3. Saidi RF, Kenari SKH. Challenges of organ shortage for transplantation: solutions and opportunities. Int J Organ Transplant Med. 2014;5(3):87-96.

4. Xia Y, Nivet E, Sancho-Martinez I, Gallegos T, Suzuki K, Okamura D, et al. Directed differentiation of human pluripotent cells to ureteric bud kidney progenitor-like cells. Nat Cell Biol. 2013;5(12):1507-15.

5. Taguchi A, Kaku Y, Ohmori T, Sharmin S, Ogawa M, Sasaki H, et al. Redefining the in vivo origin of metanephric nephron progenitors enables generation of complex kidney structures from pluripotent stem cells. Cell Stem Cell. 2014;14(1):53-67.

6. Freedman BS. Modeling kidney disease with iPS cells. Biomark Insights. 2015:10(Suppl 1):153-69.

7. Lam AQ, Freedman BS, Morizane R, Lerou PH, Valerius MT, Bonventre JV. Rapid and efficient differentiation of human pluripotent stem cells into intermediate mesoderm that forms tubules expressing kidney proximal tubular markers. J Am Soc Nephrol. 2014;25(6):1211-25.

8. Schutgens F, Verhaar MC, Rookmaaker MB. Pluripotent stem cell-derived kidney organoids: an in vivo-like in vitro technology. Eur J Pharmacol. 2016; 790:12-20.

9. Little MH. Generating kidney tissue from pluripotent stem cells. Cell Death Discovery. 2016;2:16053.

10. Al-Awqati Q, Oliver JA. Stem cells in the kidney. Kidney Int. 2002;61 (2):387-95.

11. Kobayashi A, Mugford JW, Krautzberger AM, Naiman N, Liao J, McMahon AP. Identification of a multipotent self-renewing stromal progenitor population during mammalian kidney organogenesis. Stem Cell Reports. 2014;3(4):650-62.

12. Combes AN, Wilson S, Phipson B, Binnie BB, Ju A, Lawlor KT, et al. Haploinsufficiency for the Six2 gene increases nephron progenitor proliferation promoting branching and nephron number. Kidney Int. 2017; 17:30763-69.

13. Buzhor E, Omer D, Harari-Steinberg O, Dotan Z, Vax E, Pri-Chen S, et al. Reactivation of NCAM1 defines a subpopulation of human adult kidney epithelial cells with clonogenic and stem/progenitor properties. Am J Pathol. 2013;183(5):1621-33.

14. Metsuyanim S, Harari-Steinberg O, Buzhor E, Omer D, Pode-Shakked N, BenHur $\mathrm{H}$, et al. Expression of stem cell markers in the human fetal kidney. PLoS One. 2009;4(8):e6709.

15. Schedl A. Renal abnormalities and their developmental origin. Nat Rev Gen. 2007:8:791-802

16. Higgins JP, Wang L, Kambham N, Montgomery K, Mason V, Vogelmann SU, et al. Gene expression in the normal adult human kidney assessed by complementary DNA microarray. Mol Biol Cell. 2004;15(2):649-56.

17. Georgas KM, Chiu HS, Lesieur E, Rumballe BA, Little MH. Expression of metanephric nephron-patterning genes in differentiating mesonephric tubules. Dev Dyn. 2011;240(6):1600-12.

18. Hendry C, Rumballe B, Moritz K, Little MH. Defining and redefining the nephron progenitor population. Pediatr Nephrol. 2011;26(9):1395-406.
19. Casiraghi F, Perico N, Cortinovis M, Remuzzi G. Mesenchymal stromal cells in renal transplantation: opportunities and challenges. Nat Rev Nephrol. 2016; 12(4):241-53.

20. Hamza AH, Al-Bishri WM, Damiati LA, Ahmed HH. Mesenchymal stem cells: a future experimental exploration for recession of diabetic nephropathy. Ren Fail. 2017;39(1):67-76.

21. Večerić-Haler Ž, Cerar A, Perše M. (Mesenchymal) Stem cell-based therapy in cisplatin induced acute kidney injury animal model: risk of immunogenicity and tumorigenicity. Stem Cells Int. 2017;2017:7304643.

22. Guillot PV, Gotherstrom C, Chan J, Kurata H, Fisk NM. Human first-trimester fetal MSC express pluripotency markers and grow faster and have longer telomeres than adult MSC. Stem Cells. 2007;25(3):646-54.

23. Romagnani P. Kidney regeneration: any prospects? Contrib Nephrol. 2011; 170:228-36

24. Cananzi M, De Coppi P. CD117+ amniotic fluid stem cells: state of the art and future perspectives. Organ. 2012;8(3):77-88.

25. Perin L, Giuliani S, Jin D, Sedrakyan S, Carraro G, Habibian R, et al. Renal differentiation of amniotic fluid stem cells. Cell Prolif. 2007;40:936-48.

26. Perin L, Sedrakyan S, Giuliani S, Da Sacco S, Carraro G, Shiri L, et al. Protective effect of human amniotic fluid stem cells in an immunodeficient mouse model of acute tubular necrosis. PLoS One. 2010;5(2):e9357.

27. Sedrakyan S, Da Sacco S, Milanesi A, Shiri L, Petrosyan A, Varimezova R, et al Injection of amniotic fluid stem cells delays progression of renal fibrosis. J Am Soc Nephrol. 2012;23(4):661-73.

28. Rosner M, Schipany K, Gundacker C, Shanmugasundaram B, Li K, Fuchs C, et al. Renal differentiation of amniotic fluid stem cells: perspectives for clinical application and for studies on specific human genetic diseases. Eur J Clin Investig. 2012;42:677-84.

29. Hauser PV, De Fazio R, Bruno S, Sdei S, Grange C, Bussolati B, Benedetto C, Camussi G. Stem cells derived from human amniotic fluid contribute to acute kidney injury recovery. Am J Pathol. 2010;177(4):2011-21.

30. Siegel $N$, Rosner $M$, Unbekandt $M$, Fuchs $C$, Slabina $N$, Dolznig $H$, et al. Contribution of human amniotic fluid stem cells to renal tissue formation depends on mTOR. Hum Mol Genet. 2010;19(17):3320-31.

31. De Coppi P, Bartsch G Jr, Siddiqui MM, Xu T, Santos CC, Perin L, et al. Isolation of amniotic stem cell lines with potential for therapy. Nat Biotechnol. 2007;25(1):100-6.

32. Spitzhorn LS, Rahman MS, Schwindt L, Ho HT, Wruck W, Bohndorf M, et al. Isolation and molecular characterization of amniotic fluid-derived mesenchymal stem cells obtained from caesarean sections. Stem Cells Int. 2017;2017:5932706.

33. Loukogeorgakis SP, De Coppi P. Amniotic fluid stem cells: the known, the unknown, and potential regenerative medicine applications. Stem Cells. 2017:35:1663-73.

34. Underwood MA, Gilbert WM, Sherman MP. Amniotic fluid: not just fetal urine anymore. J Perinatol. 2005;25:341-8.

35. Arcolino FO, Zia S, Held K, Papadimitriou E, Theunis K, Bussolati B, et al Urine of preterm neonates as a novel source of kidney progenitor cells. J Am Soc Nephrol. 2016;27(9):2762-70.

36. Zhang D, Wei G, Li P, Zhou X, Zhang Y. Urine-derived stem cells: a nove and versatile progenitor source for cell-based therapy and regenerative medicine. Genes Dis. 2014;1(1):8-17.

37. Da Sacco S, Perin L, Sedrakyan S. Amniotic fluid cells: current progress and emerging challenges in renal regeneration. Pediatr Nephrol. 2017;1-11.

38. Siegel N, Valli A, Fuchs C, Rosner M, Hengstschläger M. Induction of mesenchymal/epithelial marker expression in human amniotic fluid stem cells. Reprod BioMed Online. 2009;19(6):838-46.

39. Zhou T, Benda C, Duzinger S, Huang Y, Li X, Li Y, et al. Generation of induced pluripotent stem cells from urine. J Am Soc Nephrol. 2011;22(7):1221-8.

40. Bohndorf M, Ncube A, Spitzhorn LS, Enczmann J, Wruck W, Adjaye J. Derivation and characterization of integration-free iPSC line ISRM-UM51 derived from SIX2-positive renal cells isolated from urine of an African male expressing the CYP2D6 ${ }^{*} 4 /{ }^{*} 17$ variant which confers intermediate drug metabolizing activity. Stem Cell Res. 2017;25:18-21.

41. Gentleman C, Carey VJ, Bates DM, et al. Bioconductor: open software development for computational biology and bioinformatics. Genome Biol. 2004;5(10):R80.

42. Gautier L, Cope L, Bolstad BM, Irizarry RA. affy-analysis of Affymetrix GeneChip data at the probe level. Bioinformatics. 2004;20:307-15.

43. Huang DW, Sherman BT, Lempicki RA. Systematic and integrative analysis of large gene lists using DAVID bioinformatics resources. Nat Protoc. 2009;4(1):44-57. 
44. Kanehisa M, Furumichi M, Tanabe M, et al. KEGG: new perspectives on genomes, pathways, diseases and drugs. Nucleic Acids Res. 2017;45(D1): D353-61.

45. Moschidou D, Drews K, Eddaoudi A, Adjaye J, De Coppi P, Guillot PV. Molecular signature of human amniotic fluid stem cells during fetal development. Curr Stem Cell Res Ther. 2013;8(1):73-81.

46. Zhang Y, McNeill E, Tian H, Soker S, Andersson KE, Yoo JJ, et al. Urine derived cells are a potential source for urological tissue reconstruction. J Urol. 2008;180:2226-33.

47. Lang R, Liu G, Shi Y, Bharadwaj S, Leng X, Zhou X, et al. Self-renewal and differentiation capacity of urine-derived stem cells after urine preservation for 24 hours. PLoS One. 2013;8(1):e53980.

48. Bharadwaj S, Liu G, Shi Y, Wu R, Yang B, He T, et al. Multipotential differentiation of human urine-derived stem cells: potential for therapeutic applications in urology. Stem Cells. 2013;31(9):1840-56.

49. Kim EY, Page P, Dellefave-Castillo LM, McNally EM, Wyatt EJ. Direct reprogramming of urine-derived cells with inducible MyoD for modeling human muscle disease. Skelet Muscle. 2016;6:32

50. Qin D, Long T, Deng J, Zhang Y. Urine-derived stem cells for potential use in bladder repair. Stem Cell Res Ther. 2014;5(3):69.

51. Sutherland GR, Bain AD. Culture of cells from the urine of newborn children. Nature. 1972:239:231

52. Zagoura DS, Trohatou O, Bitsika V, Makridakis M, Pappa Kl, Vlahou A, et al. AFMSCs fate can be regulated by culture conditions. Cell Death Dis. 2013;4:e571.

53. Bussolati B, Camussi G. Therapeutic use of human renal progenitor cells for kidney regeneration. Nat Rev Nephrol. 2015;11:695-706.

54. Wang H, Gomez JA, Klein S, Zhang Z, Seidler B, Yang Y, et al. Adult rena mesenchymal stem cell-like cells contribute to juxtaglomerular cell recruitment. J Am Soc Nephrol. 2013;24(8):1263-73.

55. Rosenblum ND. Developmental biology of the human kidney. Semin Fetal Neonatal Med. 2008;13(3):125-32.

56. Tong GX, Yu WM, Beaubier NT, Weeden EM, Hamele-Bena D, Mansukhani $M M$, et al. Expression of PAX8 in normal and neoplastic renal tissues: an immunohistochemical study. Mod Pathol. 2009;22(9):1218-27.

57. Tojo A, Kinugasa S. Mechanisms of glomerular albumin filtration and tubular reabsorption. Int J Nephrol. 2012;2012:481520.

58. Eyre J, loannou K, Grubb BD, Saleem MA, Mathieson PW, Brunskill NJ, et al. Statin-sensitive endocytosis of albumin by glomerular podocytes. Am J Physiol Renal Physiol. 2007;292:F674-81.

59. Xinaris C, Benedetti V, Novelli R, Abbate M, Rizzo P, Conti S, et al. Functional human podocytes generated in organoids from amniotic fluid stem cells. J Am Soc Nephrol. 2016;27(5):1400-11.

60. Musah S, Mammoto A, Ferrante TC, Jeanty SSF, Hirano-Kobayashi M, Mammoto T, et al. Mature induced-pluripotent-stem-cell-derived human podocytes reconstitute kidney glomerular-capillary-wall function on a chip. Nat Biomed Eng. 2017;1:0069.

61. Depping R, Schindler SG, Jacobi C, Kirschner KM, Scholz H. Nuclear transport of Wilms' tumour protein Wt1 involves importins a and $\beta$. Cell Physiol Biochem. 2012;29(1-2):223-32.

62. Park JS, Ma W, O'Brien LL, Chung E, Guo JJ, Cheng JG, et al. Six2 and Wnt regulate self-renewal and commitment of nephron progenitors through shared gene regulatory networks. Dev Cell. 2012;23(3):637-51.

63. Zeisberg M. Bone Morphogenic protein 7 and the kidney: current concepts and open questions. Nephrol Dial Transplant. 2006:21:568-73.

64. Little MH, McMahon AP. Mammalian kidney development: principles, progress, and projections. Cold Spring Harb Perspect Biol. 2012;4:4.

\section{Ready to submit your research? Choose BMC and benefit from:}

- fast, convenient online submission

- thorough peer review by experienced researchers in your field

- rapid publication on acceptance

- support for research data, including large and complex data types

- gold Open Access which fosters wider collaboration and increased citations

- maximum visibility for your research: over $100 \mathrm{M}$ website views per year

At BMC, research is always in progress.

Learn more biomedcentral.com/submissions 